\title{
Gender-related behaviors in group-living stumptail macaques
}

\author{
KEES NIEUWENHUIJSEN, A. KOOS SLOB, and JACOB J. VAN DER WERFF TEN BOSCH \\ Erasmus University, Rotterdam, The Netherlands
}

\begin{abstract}
This paper describes gender-related behaviors in a colony of stumptail macaques observed over a 3-year period. Information about dominance positions, proximity preferences, sexual behaviors, aggression, social and solitary play, and social grooming of male and female monkeys at different ages is included.
\end{abstract}

The work presented here represents a 3-year study on social behavior, reproduction, and puberty in stumptail macaques (Macaca arctoides). The stumptail macaque is a fascinating primate species. It differs in various respects from two more commonly known macaque species, the rhesus monkey ( $M$. mulatta) and the Japanese macaque (M. fuscata). These latter two species have been studied extensively, both in the wild and in captivity.

Reproduction in rhesus and Japanese macaques is seasonal: copulatory behavior is restricted to the fall months, and births take place half a year later (Lindburg, 1987). During the mating season, plasma testosterone levels in adult males are higher than at other times of the year (Gordon, Rose, \& Bernstein, 1976; Nigi, Tiba, Yamamoto, Floescheim, \& Ohsawa, 1980). Females copulate most frequently during the periovulatory part of their ovarian cycles (Enomoto, Seiki, \& Haruki, 1979; Gordon, 1981; for further references, see Nieuwenhuijsen, de Neef, \& Slob, 1986; Nieuwenhuijsen, BonkeJansen, de Neef, van der Werff ten Bosch, \& Slob, 1987; Nieuwenhuijsen, Lammers, de Neef, \& Slob, 1985).

In contrast, stumptail macaques breed year round. Testosterone levels in the males do not show a systematic seasonal pattern and are not correlated with copulatory activity. Variations in copulation frequencies over the female's ovarian cycle are less pronounced than in rhesus and Japanese macaques (Nieuwenhuijsen, de Neef, et al., 1987; Nieuwenhuijsen et al., 1986; Nieuwenhuijsen et al., 1985).

Perhaps the most intriguing aspect of the sexual behavior of stumptail macaques is the high ejaculatory potential of the males: they may copulate and ejaculate dozens of times on a single day. The highest number ever

The opportunity to carry out this research was generously offered by Organon International BV, Oss, The Netherlands. Thanks are due to the following people who have in their diverse ways contributed to the work reported here: M. E. Y. Bonke-Jansen, E. Broekhuijzen, G. van Cappellen, B. Drukker, W. Hagedoorn, J. A. R. A. M. van Hooff, A. J. J. C. Lammers, K. J. de Neef, M. P. Ooms, P. E. Schenck, and P. D. M. van der Vaart. Address correspondence to A. K. Slob, Department of Endocrinology, Growth \& Reproduction, Faculty of Medicine, P.O. Box 1738, 3000 DR Rotterdam, The Netherlands. recorded was 59 ejaculations by one male during $6 \mathrm{~h}$ (Estep et al., 1988; Nieuwenhuijsen et al., 1986). This is much higher than the maximum rates reported for other macaque species, which are all less than 10 times per day (e.g., Bielert \& Goy, 1973; Nadler \& Rosenblum, 1973; see also Slob \& Nieuwenhuijsen, 1980).

Very little is known about stumptail macaques in their natural environment (Fooden, Guoqiang, Zongren, \& Yingxiang, 1985). We had the opportunity to study a large group of stumptails living in captivity. It was possible to collect physiological data and to make behavioral observations. This paper focuses on sexual dimorphism in the animals' development and frequencies of various sociosexual behaviors. A behavior can be considered sexually dimorphic, or gender related, when it is "displayed more frequently, more readily, or more intensely by one sex than by the other"' (Goy \& Goldfoot, 1973, p. 169).

Other details of the study are discussed in separate publications (Estep et al., 1988; Nieuwenhuijsen, BonkeJansen, et al., 1988; Nieuwenhuijsen, Bonke-Jansen, et al., 1987; Nieuwenhuijsen et al.,1986; Nieuwenhuijsen, de Neef, et al., 1987; Nieuwenhuijsen et al., 1985; Nieuwenhuijsen, Slob, \& de Neef, 1988). These publications also give a more complete listing of the relevant literature than does the present overview article. An excellent survey on gender differences in primates has been given by Fedigan (1982).

\section{METHOD}

The study was conducted at the stumptail macaque colony of Organon International BV in Oss, The Netherlands. The original members of the colony had been obtained from several European laboratories between 1970 and 1977. Some of them were probably feral-born. The first birth in Oss occurred in 1972. At first, the monkeys lived individually or in small groups in indoor cages. A large outdoor cage with indoor facilities became available in 1978 (see Figures 1 and 2). The animals have lived there since at least 1979.

At the start of the study, in 1980 , the study group consisted of 70 individuals: 27 males and 43 females, ranging in age from 0 to about 15 years. During the 3 years of the study, 11 males and 16 females were born, while 2 males and 1 female died. Five males and 11 females reached adulthood. Males were considered adult 


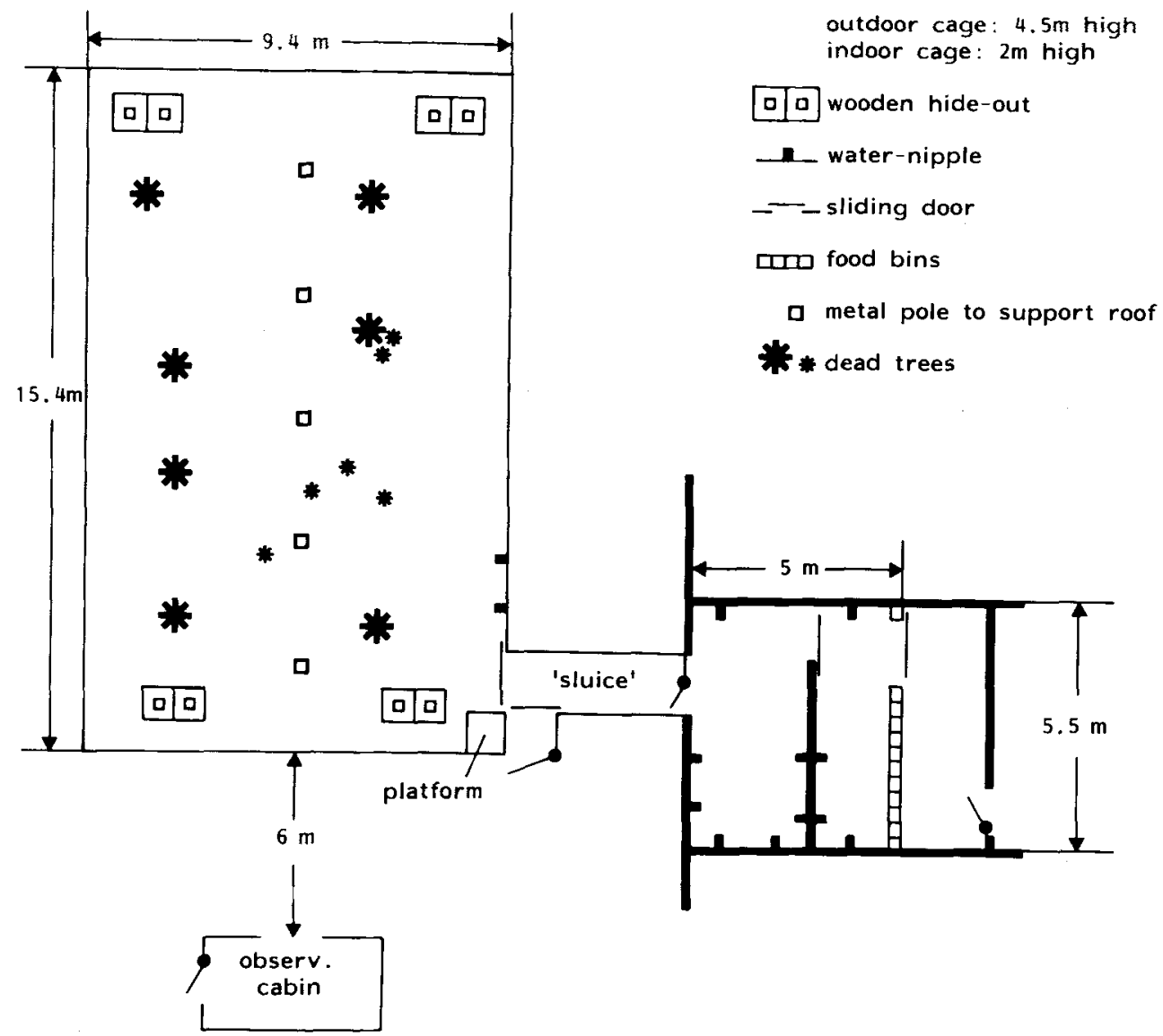

Figure 1. Plan view of the outdoor cage and indoor facilities. It is possible to walk alongside the cage. The wooden hideouts have one open side, facing the observation cabin. From "Reproduction and Social Rank in Female Stumptail Macaques (Macaca arctoides)" by K. Nieuwenhuijsen, A. J. J. C. Lammers, K. J. de Neef, and A. K. Slob, 1985, International Journal of Primatology, 6, p. 80. Copyright 1985 by Plenum Press. Reprinted with permission.

when they were first observed to produce semen, and females when they first ovulated.

More than $1,000 \mathrm{~h}$ were spent on behavioral observations. Behaviors were scored using the "all occurrences" technique for sexual behaviors, aggression, and display, and the "scan sample" technique for proximity, grooming, and play (see Altmann, 1974, for a description of observation techniques).

Physiological data collected included body weight, testis size, and blood samples for hormone determination. Stumptail macaques are easy to handle; capturing individuals for weighing or bleeding did not upset the group.

\section{RESULTS AND DISCUSSION}

\section{Somatic Data}

At birth, males and females had roughly the same body weights (average $=0.50 \mathrm{~kg}$ for both sexes). During the first 3 years of life, males and females grew at equal rates, and body weights around the third birthday averaged $5.2 \mathrm{~kg}$ for both sexes. At puberty, gender differences started to emerge.

An early sign of puberty in males was the descent of the testes into the scrotal sac, which occurred at an aver- age age of 3.3 years, and coincided with the onset of the pubertal rise in plasma testosterone. Testicular descent was followed by a pubertal growth spurt in body weight (Figure 3). At a mean age of 4.1 years, ejaculate was first produced. During the following year, the testes reached the adult size of about $40 \mathrm{ml}$ (Figure 3).

In females, no clear external signs of puberty were found. Menstrual bleedings are short in duration and difficult to detect. Perineal swellings, which are obviously present in many primate species, such as baboons and chimpanzees, do not occur in stumptail macaques. The data of first ovulation (a late sign of puberty) could be estimated on the basis of weekly progesterone data, and occurred at an average age of 3.7 years. The first ovulation was preceded by a growth spurt in body weight. Females first conceived at an average age of 4.2 years, and first gave birth 6 months thereafter.

From the typical examples shown in Figure 3, it can be seen that males gained much more weight during puberty than females. In adults, male and female body weights averaged 11.5 and $8.7 \mathrm{~kg}$, respectively. The peak of pubertal growth spurt in body weight occurred at a 


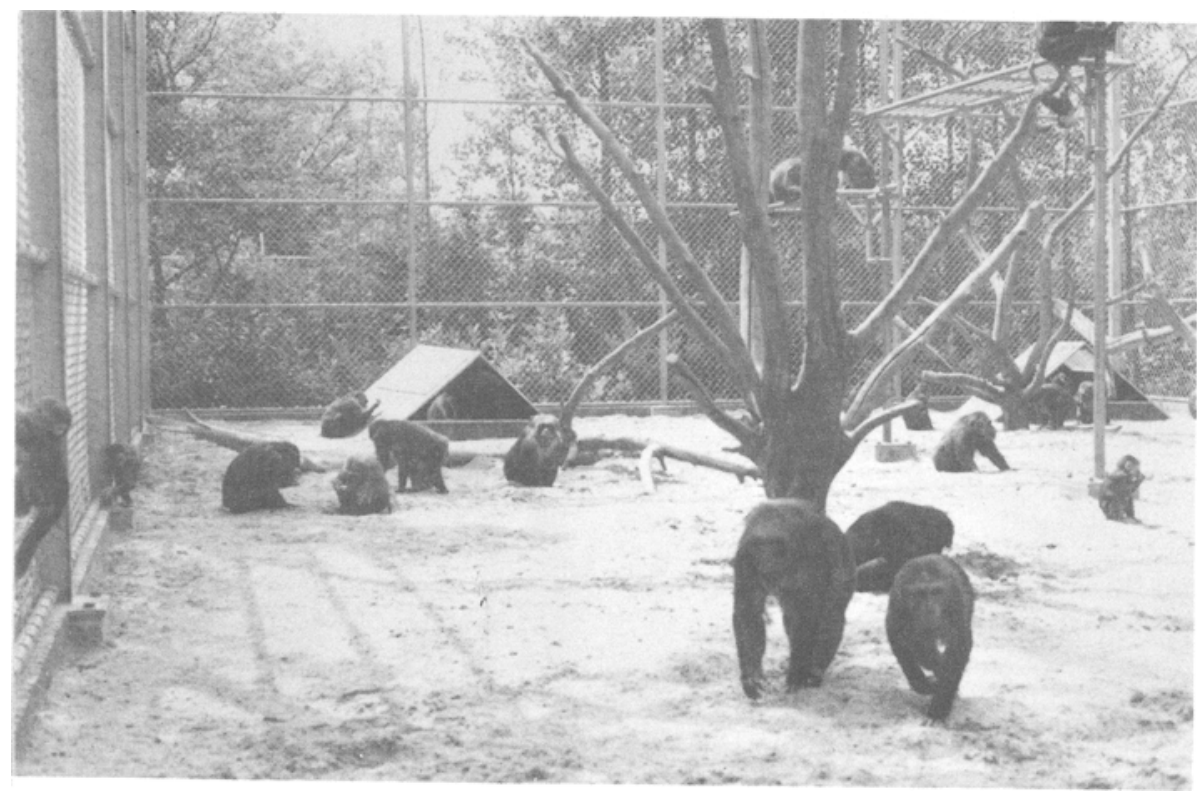

Figure 2. Stumptails in the outdoor cage. In the distance two hideouts can be seen.
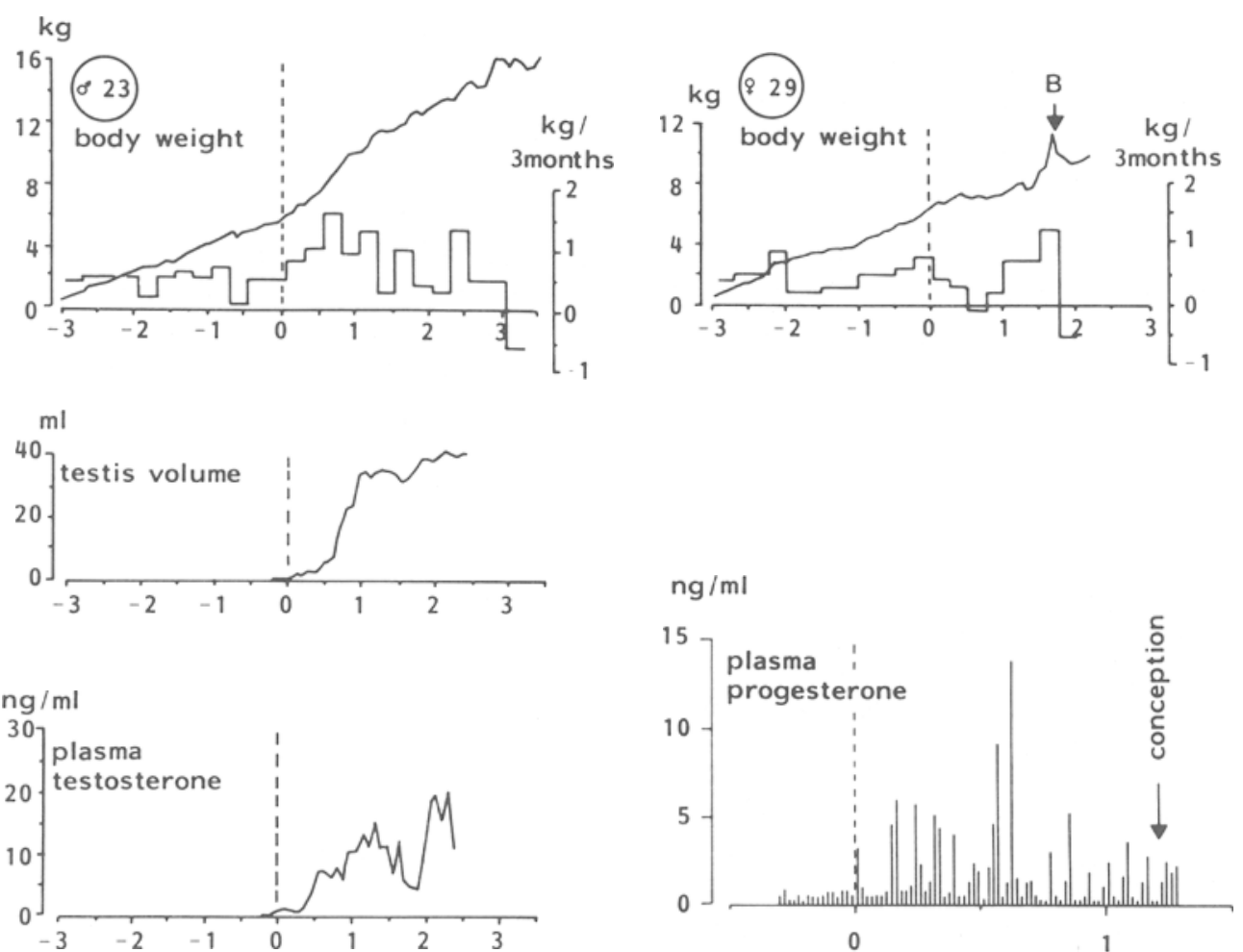

Figure 3. Physiological development in a male (left) and a female (right) stumptail macaque. Two typical examples are shown. Body weights are plotted per month, and weight increments per 3 months. Blood samples were taken monthly in males (for testosterone determination) and weekly in females (for progesterone determination). B = birth of a young. Redrawn from "Testosterone, Testis Size, Seasonality, and Behavior in GroupLiving Stumptail Macaques (Macaca arctides)" by K. Nieuwenhuijsen, K. J. de Neef, J. J. van der Werff ten Bosch, and A. K. Slob, 1987, Hormones \& Behavior, 21. 
mean age of 3.0 years in females, and 0.9 years later in males. Reproductive capacity (first semen produced or first conception) was reached at about the same age in both sexes (Nieuwenhuijsen, Bonke-Jansen, et al., 1987).

In most young females, the first ovulation was followed by several (from 0 to 30 ) nonconceptive ovulatory cycles, despite regular copulations with adult males. The female represented in Figure 3 went through 14 ovulatory ovarian cycles (as indicated by 14 progesterone elevations) before she conceived. Also, in fully adult females, most conceptions were preceded by a number of nonconceptive ovulatory cycles. Stumptail macaques seem to have a lower fecundity than rhesus monkeys (Nieuwenhuijsen et al., 1986).

\section{Social Structure}

Dominance relationships among adults. Winner/loser outcomes of agonistic dyads were used to construct a dominance matrix. In an agonistic dyad, the animal that was the last to perform submissively (avoid, shrink, take flight, crouch, bare teeth) was considered to be the loser. Only pure dyads (no interference by a third animal) observed while the complete group was present in the outdoor cage, were scored in the dominance matrix.

Among the fully adult males $(n=18)$, a clear dominance hierarchy existed: one male (named James) always defeated his opponents in fights, the second-ranking male (Herman) could defeat all other males except James, and so forth. In this way, all males could be ranked in a strictly linear order. James was considered the alpha male, or leader of the group.

Winner/loser outcomes of agonistic interactions among the fully adult females in the group $(n=27)$ revealed a similar linear hierarchy. A female named Els held the highest position.

It was difficult to rank both males and females in one overall hierarchy: differences in dominance rank were often tenuous. It was obvious, however, that 4 adult males outranked all other animals and thus formed the top of the hierarchy. The middle part of the hierarchy consisted mainly of females, and both males and females were found at the bottom. Thus, a number of adult males were subordinate to most of the adult females. Although dominance relationships among the adults remained stable, changes did occur in the dominance positions of peripubertal animals relative to the adults.

Dominance hierarchies based on agonistic interactions have been described for numerous primate groups, both in captivity and in the wild. The pattern found in other captive macaque groups was basically the same as in our colony, with a few males at the top, but also some males at the bottom of the hierarchy (Alexander \& Bowers, 1969; Angst, 1975; Bernstein, 1969; de Waal, 1977; Johnson, Modahl, \& Eaton, 1982). Among some macaques in the wild, however, all adult males take positions in the top of the hierarchy (Angst, 1975; Deag, 1977; Taub, 1980). The females dominating adult males may be an artifact of captivity, and may not occur under natural circumstances. It should be stressed that this is not true for all types of dominance (e.g., access to food: see Simonds, 1965; Southwick, Beg, \& Siddiqi, 1965) or for all primate species (Fedigan, 1982).

In the following sections, it will become clear that for many social behaviors, dominance relationships play an important role. For example, aggression and copulation are significantly correlated with dominance rank.

Dominance relationships of peripubertal animals. Dominance relationships between prepubertal animals reflected maternal dominance relationships: sons and daughters of high-ranking mothers dominated same-aged sons and daughters of low descent. This correlation with maternal rank persisted through puberty and into adulthood, for both males and females. Dominance positions relative to fully adult animals changed around the time of puberty.

Before puberty, young males ranked among the lowranking adult males. They rarely, if ever, attacked highand middle-ranking adult males (ranks 1 through 8 ), and were always defeated when they had conflicts with such adults. At the approach of puberty, the young males increasingly directed attacks toward middle-ranking adultmales (ranks 5 through 8 ), and eventually began to defeat them. Thus, pubertal males gradually rose in the hierarchy from low to middle positions. All but one of the young males remained subordinate to the 4 highest ranking adult males.

One young male (Eelco) defeated not only the middleranking males, but also the ones ranking above them, including the alpha male James. Thus, Eelco became the new leader of the group at the age of 5.5 years. James was about 15 years old at that time. Interestingly, Eelco was a son of Els, the highest ranking mother in the group. This change in leadership took place some 7 months after the official study had ended. All data presented here refer to the time when James was alpha male (except where noted).

The dominance positions of young females also changed around the time of puberty. Before that time, the exact dominance positions relative to adult females were vague: prepubertal females ranked somewhere below their mother. About a year before first ovulation, young females started to attack and defeat all adult females that ranked below their own mothers. Thus, most young females eventually reached a dominance position directly below their own mothers. However, some (4 out of 15) young females outranked their mothers. One of these was Erica, a daughter of Els. She became the highest ranking female when she was 6 years of age. Each female's dominance rank stabilized at some time during the 2 years following first ovulation.

These changes in dominance position occurred during a period in which some dramatic physiological changes took place: testosterone levels in the males rose, the females started to ovulate, and both sexes went through a pubertal growth spurt. However, there was no statistically significant correlation between the timings of these events. 
In females, first ovulation did not coincide with an abrupt change in the process of rank stabilization. Neither the rapidity of a male's rise in the hierarchy nor his final dominance position could be predicted on the basis of his testosterone pattern or his growth curve. Wilson and Vessey (1968) found that both intact and castrated rhesus males rose in rank at 3 to 5 years of age, which indicates that androgens are not a crucial factor for the dominance rise.

Proximity relationships. The social structure of a primate group can be described not only in terms of dominance relationships, but also in terms of proximity preferences. This aspect of social behavior has been studied in a number of feral macaque groups, but has received little attention in studies on captive groups. The studies on feral groups revealed some interesting gender differences with regard to proximity preferences.

In a number of species of wild macaques and baboons, a "central-peripheral" structure has been reported; that is, the core of a group is formed by high- and middleranking females, their young offspring, and a few topranking adult males, whereas other adult males, most pubertal males, and some low-ranking females remain at some distance (Angst, 1975; Kaufmann, 1967; Southwick et al., 1965; Sugiyama, 1960). Peripheral males may eventually migrate toward another group, but females stay in their natal group for the rest of their lives (Packer, 1979). An occasional young male may remain in the central group, and reach a high dominance rank (Koford, 1963).

To determine proximity preferences in our colony, we took scan samples of who was sitting within arm's reach of whom. By the end of the study, a proximity score (percentage of scan samples) could be calculated for each pair of individuals. The average and median scores per pair of adults were $10 \%$ and $8 \%$, respectively. Infants were not considered here; they spent most of their time close to their mothers.

There appeared to be a cluster of 7 individuals which showed a clear proximity preference for each other: within each pair $(n=21)$, the score was higher than $30 \%$. These 7 individuals all had high dominance positions: they were the adult males ranked 1 and 2 ; the adult females ranked $1,2,3$, and 7 ; and the pubertal female ranked 1 . These 7 animals were considered the "social core" of the colony. Their physical position was not necessarily the middle of the cage; in fact, they could usually be found in one of the corners.

There were several other pairs with scores over $30 \%$, but these pairs did not form any large aggregate. If another criterion was used (e.g., 20\%), several other, partially overlapping, clusters could be distinguished.

High- and middle-ranking adult females which were not core individuals often had fairly high proximity scores with core individuals $(10 \%-25 \%)$, but low-ranking females did not (around 5\%). Thus, among adult females, proximity position correlated with dominance position. No such correlation was found for the adult males. In general, they were less frequently found near core individuals than were adult females.

The animals which had the lowest scores with core individuals-males of various dominance ranks and the bottom-ranking females-did have relatively high proximity scores with each other $(10 \%-20 \%$ in most pairs). Thus, they formed a (not very cohesive) peripheral cluster.

The limited space in our colony prevented a real central-peripheral structure to develop. Still, the gender differences found in our group resembled those in the wild: females showed proximity preferences for one another, and thus formed the core of the group, whereas males (except the top-ranking ones) led a more peripheral life.

To our knowledge, only one previous study of this kind has been done on animals in captivity: Alexander and Bowers (1969) observed a group of Japanese macaques, which was about as large as our study group but had a larger living space. In this group, the central-peripheral structure could not be demonstrated, except during feeding. This may be due to the fact that Alexander and Bowers made their observations in the middle of summer. We took scan samples all year round, and noted that on hot days individuals sat dispersed throughout the cage, whereas on cold days they huddled together in clusters of 10 to 30 individuals, in which proximity preferences were obvious.

Considering the situation in the wild, one would expect that, in our colony, young males would gradually move toward the peripheral cluster. However, this would not be expected from young females. Peripheralization in females was indeed absent: pubertal females had the same proximity preferences as their mothers, and these persisted into adulthood.

Pubertal males also showed proximity preferences similar to those of their mothers. This changed in some of the 12 males which could be studied in early adulthood (between 4 and 7 years of age). Three of these 12 were sons of more or less peripheral mothers, and became peripheral themselves. The other 9 were sons of core mothers or of mothers which scored high on proximity with core individuals. Their proximity patterns as young adults were highly divergent: 3 of them were clearly peripheral, 3 others clearly preferred core individuals, and the remaining 3 showed an intermediate pattern.

It seems, therefore, that a shift toward the periphery may also occur in captivity, although not all males take part in it, and (at least in our colony) it takes place well after puberty.

\section{Aggression}

Aggression frequency. The frequency of aggression in young animals showed no gender difference. During the first year of life, infants rarely engaged in aggressive interactions (during the first 4 months, such interactions were never seen); however, 2-year-olds had frequencies comparable to those of adults. At puberty, no systematic 
rise or fall in overall aggressive activity was seen, but the identity of aggressive opponents did shift, from youngsters toward adults.

High-ranking pubertal animals tended to show more aggression than lower ranking peers, but for neither sex was the correlation statistically significant. Interestingly, Eelco, the alpha-male-to-be, was by far the most aggressive young animal. This was already evident before he reached puberty.

In adults, the correlations of aggression with dominance rank were highly significant, both for males and females, and both for aggression performed (positively correlated) and aggression received (negatively correlated). This seems self-evident, as agonistic interactions were used to determine dominance positions. However, "dominance" interactions did not necessarily involve aggression (e.g., bared teeth in response to a nonaggressive approach), and aggressive interactions did not necessarily reveal a difference in dominance.

Among the adults, there was a significant gender difference in aggressiveness: males scored on average $80 \%$ higher than females. This difference was due entirely to the 8 highest ranking adult males, who were also dominant over all or most of the females. Their individual scores varied between 1 and 2 attacks per hour. The only female with a comparable frequency was Els, the top female. If males and females of about equal rank were compared, no difference was found.

Aggression received showed no gender difference. Individual frequencies varied from almost 0 for the alpha male James, to between 1 and 2 attacks per hour, for the bottom-ranking males and females.

Aggressive opponents. The identity of an animal's opponents in aggressive interactions depended mainly on dominance differences, but age and gender also played a role. Most animals in our colony showed a "preference" for aggressive opponents of roughly the same age. Before puberty, gender did not seem to play an important role: for both males and females, aggressive opponents were equally distributed over the sexes.

Among the adult animals, virtually all aggressive initiatives went down the hierarchy: only $1 \%$ of all malemale attacks and 3\% of female-female attacks were directed at a higher ranking opponent. Had directionality of aggression been used as a criterion of dominance, the hierarchy would have been the same as the present hierarchy, based on winning and losing. Similar patterns have been described for other macaque groups (Eaton \& Resko, 1974; de Waal, 1977). Among chimpanzees, however, upward aggression is much more common: in a zoo colony studied by de Waal (personal communication, 1987), one in every seven attacks was directed at a higher ranking opponent.

The analysis of aggressive conflicts between adults was complicated by the fact that animals that spent a lot of time in each other's proximity also had relatively many conflicts with each other. Aggression among kin-related animals, for instance, occurred on average three times as often as aggression among unrelated animals, whereas proximity scores resulted in a similar difference. When we corrected for this confounding factor, it appeared that females had as many conflicts with other females as with males. Adult males, on the other hand, had four times as many conflicts with other males as with females. Furthermore, the correlation between proximity and aggression was not as strong among the males as it was among the females. It seemed that males, unlike females, went out to look for same-sexed victims. This gender difference developed during puberty, when young males started to engage in more conflicts with adult males.

\section{Social Play}

Social play is one of the most frequent activities of young primates of all species. In the present study, two types of social play were distinguished: pursuit play (in which 2 or more animals chase each other, and the roles of chaser and chased may frequently switch) and roughand-tumble play (consisting of wrestling and mild bites). Scan samples were taken to monitor how often and with whom the animals played. During these samples, solitary play was also scored (manipulating stones, sticks, or other objects).

All infants in our group were often engaged in social play with each other. Play frequencies decreased at puberty for males and females. Some young adults (up to 6 years of age) infrequently participated in playful interactions, but older adults were never seen to play.

Throughout infancy and puberty, males had higher social play frequencies than did same-aged females. Pursuit play was seen about equally frequently in both sexes, but rough-and-tumble play occurred twice as often in males as in females.

Most youngsters showed a preference for playmates of their own gender. This was most obvious in males: individual scores ranged from $58 \%$ to $83 \%$ for play with individuals of the same sex. There was also a preference for same-sexed playmates among infant females $(52 \%$ to $65 \%)$, but not among pubertal females $(M=49 \%)$. These percentages have been corrected for the number of available partners.

Frequencies of solitary play also showed a gender difference: females' scores were about 2.4 times as high as those of same-aged males. As with social play, the frequencies decreased during puberty.

Our findings on social play are in line with those of many earlier studies, in that males show more play (especially rough-and-tumble play) than do females (see Fedigan, 1982, for references). However, our data on solitary play indicate that females are not necessarily less explorational than males.

\section{Social Grooming}

In contrast to social play, social grooming was an activity predominantly shown by adults. Young animals were groomed frequently (especially young infants, by their mothers), but did little grooming themselves. During puberty, grooming activity increased in females but not in males. Adult females groomed on average 2.7 times 
as often as adult males. This difference was in part due to the frequent grooming of infants by their mothers. However, a significant gender difference remained when mother-infant data were eliminated from the analysis. A similar difference was found in several other primate species (Bernstein, 1970).

In adult females, grooming frequencies (both performed and received) were positively correlated with dominance rank. This can be explained by the fact that high-ranking females spent much time in each other's proximity, whereas low-ranking females spent more time on their own, or with males, which did little grooming. Among the males, grooming frequencies did not correlate with dominance rank.

Grooming by adults was mostly directed toward animals of the same gender and of higher dominance rank. The preference for same-sexed grooming partners persisted after correction for proximity preference. Grooming upward in the hierarchy might be a means to appease potential aggressors; however, the fact that as much as $40 \%$ of all adult grooming was directed toward lower ranking partners and the observation that very young infants were highly popular as grooming recipients indicate that social grooming is not simply a submissive behavior. This is in line with earlier findings of de Waal and Luttrell (1986).

\section{Display Behavior}

Display behavior consists of powerful shaking of a tree or branch, or of the wire-mesh fence. Similar display behaviors occur in many other primate species (de Waal, 1982; Modahl \& Eaton, 1977; Wolfe, 1981). All studies on display behavior have revealed that it is a typically masculine behavior. In our colony, 17 or 18 adult males displayed, on a total of 2,151 occasions, whereas only 7 of 27 adult females were seen to display, on a total of 15 occasions.

In both sexes, about $50 \%$ of the displays were performed by the highest ranking individual. James had an average score of 1.5 per hour (other males scored 0.5 per hour at the most ), and Els displayed 0.012 times per hour, which was comparable with the display activity of lowranking adult males. When James and Els lost their top positions, the young animals that took over their positions (Eelco and Erica) became the leading displayers for their gender.

Display behaviors were first performed by 2-year-olds, often as part of play. Young females displayed as rarely as adult females. Prepubertal males displayed more often than females, but less often than adult males. Around the age of 4 years, during their rise in the dominance hierarchy, young males reached display frequencies comparable to those of middle-ranking adult males.

The function of display behavior in macaques is unclear. Modahl and Eaton (1977) and Wolfe (1981) suggested that Japanese macaque males display to attract females for copulation. This seems to be corroborated by the significant correlation between display and copulatory activity among the adult males in our colony. However, this correlation disappeared after correction for the fact that both display and copulation scores also correlated significantly with dominance rank.

\section{Sexual Behavior}

Copulations: General description. Stumptail macaques show the single-mount ejaculation pattern: their copulations usually consist of only one intromittive and ejaculatory mount. On average, intromissions among our group lasted $25 \mathrm{sec}$ (until the moment of ejaculation) and included 38 pelvic thrusts. Copulations in rhesus and Japanese macaques consist of a series of about 10 intromittive mounts (multiple-mount ejaculations). Several minutes elapse between consecutive intromissions, and each intromission lasts only a few seconds; the total number of pelvic thrusts averages about 30 or 40 .

The various components of heterosexual copulatory activity in stumptail macaques are depicted in Figure 4. The figure shows a male-initiated copulation. Copulations can also be initiated by the female, when she presents spontaneously toward her partner. Many heterosexual interactions included only the first stages seen in Figure 4. We defined a copulation as a heterosexual interaction including at least one intromission. Copulations could end without ejaculation.

Unique for the stumptail macaque is the facial expression of the male at the time of ejaculation: the "frowning round-mouthed look" (Chevalier-Skolnikoff, 1974) or "climax face" (Slob, Groeneveld, \& van der Werff ten Bosch, 1986). Ejaculation in stumptails can be easily recognized by this facial expression, which coincides with a sudden cessation of pelvic thrusts.

Occasionally, females also display such a facial expression, either during a heterosexual copulation, or when they mount another female. Laboratory studies have revealed that it coincides with uterine contractions and increased heart rate (Goldfoot, Westerborg-van Loon, Groeneveld, \& Slob, 1980; Slob et al., 1986). Therefore, it can be considered an indicator of the female orgasm (according to the criteria used by Masters \& Johnson, 1966). In the present study, this behavioral indicator of female orgasm was seen during only $16 \%$ of the ejaculatory copulation, and never during a nonejaculatory copulation. Female orgasms tended to occur most fequently in pairs that copulated relatively often. This may mean that being well adapted to one another enhances the probability of female orgasms to occur. Unfortunately, our data were insufficient to prove this theory.

Reaching back and looking back during copulation are performed by the females of numerous primate species. These behaviors were thought to be indicative of the female orgasm (Zumpe \& Michael, 1968); however, this seems unlikely, since these behaviors may already be seen during the early stages of copulation, before an intromission or even a mount has begun. Furthermore, males may look and reach back while being mounted by another male. 

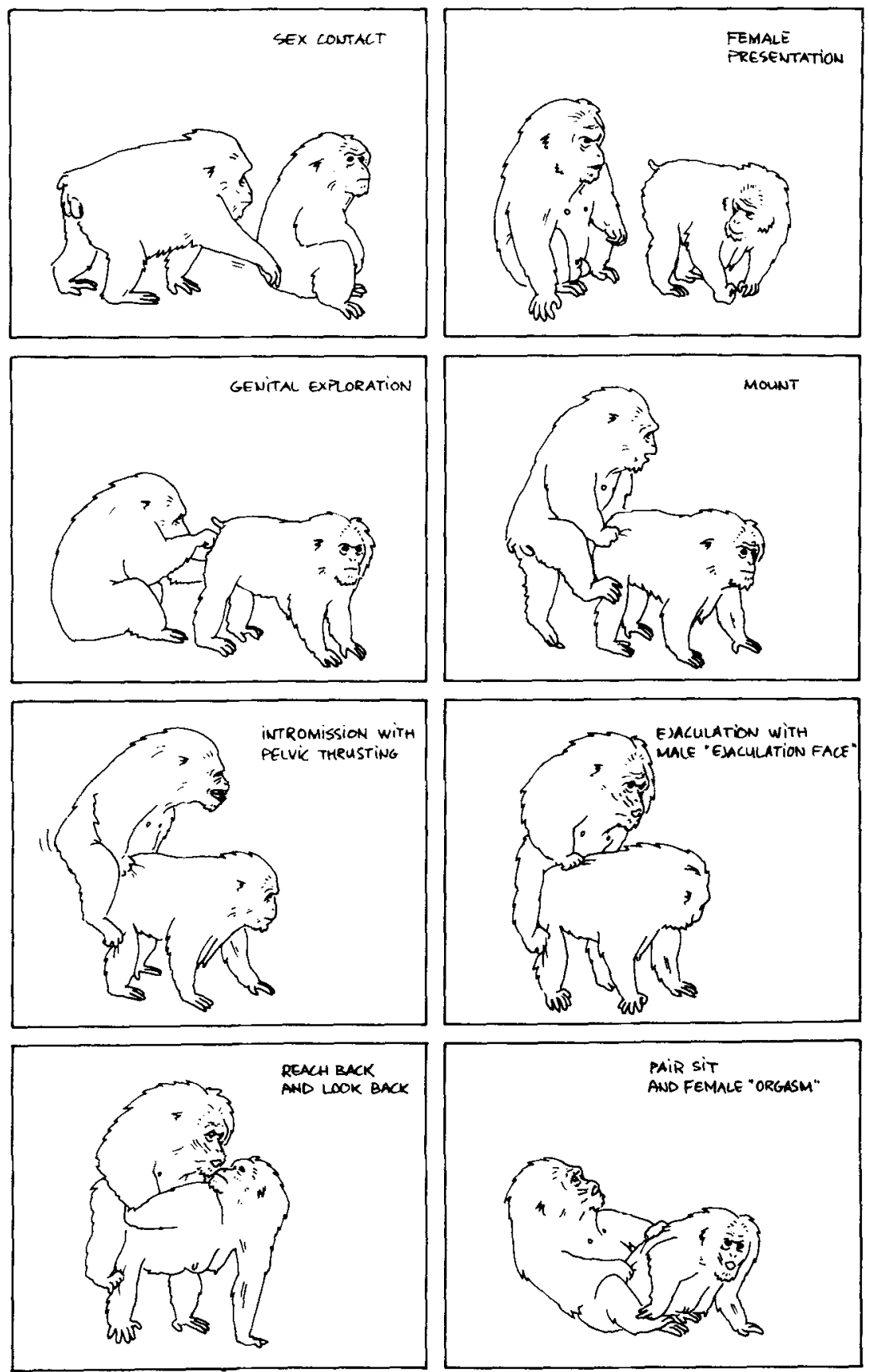

Figure 4. Eight stages of a heterosexual copulatory interaction in the stumptail macaque.

After ejaculation, the intromission usually continues for some time (up to $2 \mathrm{~min}$ ). During this time, the male's frowning round-mouthed look persists. This postejaculatory pair-sit is a species-specific feature of the stumptailmacaque. In other macaque species, the partners separate immediately after ejaculation.

Copulation frequencies of adults. In both sexes, copulation frequencies were positively correlated with dominance rank. The correlation was much stronger in males than in females: the correlation coefficients (Ken- dall's tau) were $0.739(n=18, p<.001)$ and 0.311 $(n=27, p<.05)$, respectively (Figure 5 ).

Among the adult males, copulations were subject to social control: high-ranking males did not tolerate copulations by lower ranking males. The alpha male was the only adult male that could copulate in full view of other animals. Other adult males had to copulate surreptitiously. If a higher ranking male discovered such a surreptitious copulation, he would interrupt it by approaching and sometimes attacking the couple. This explains why the 


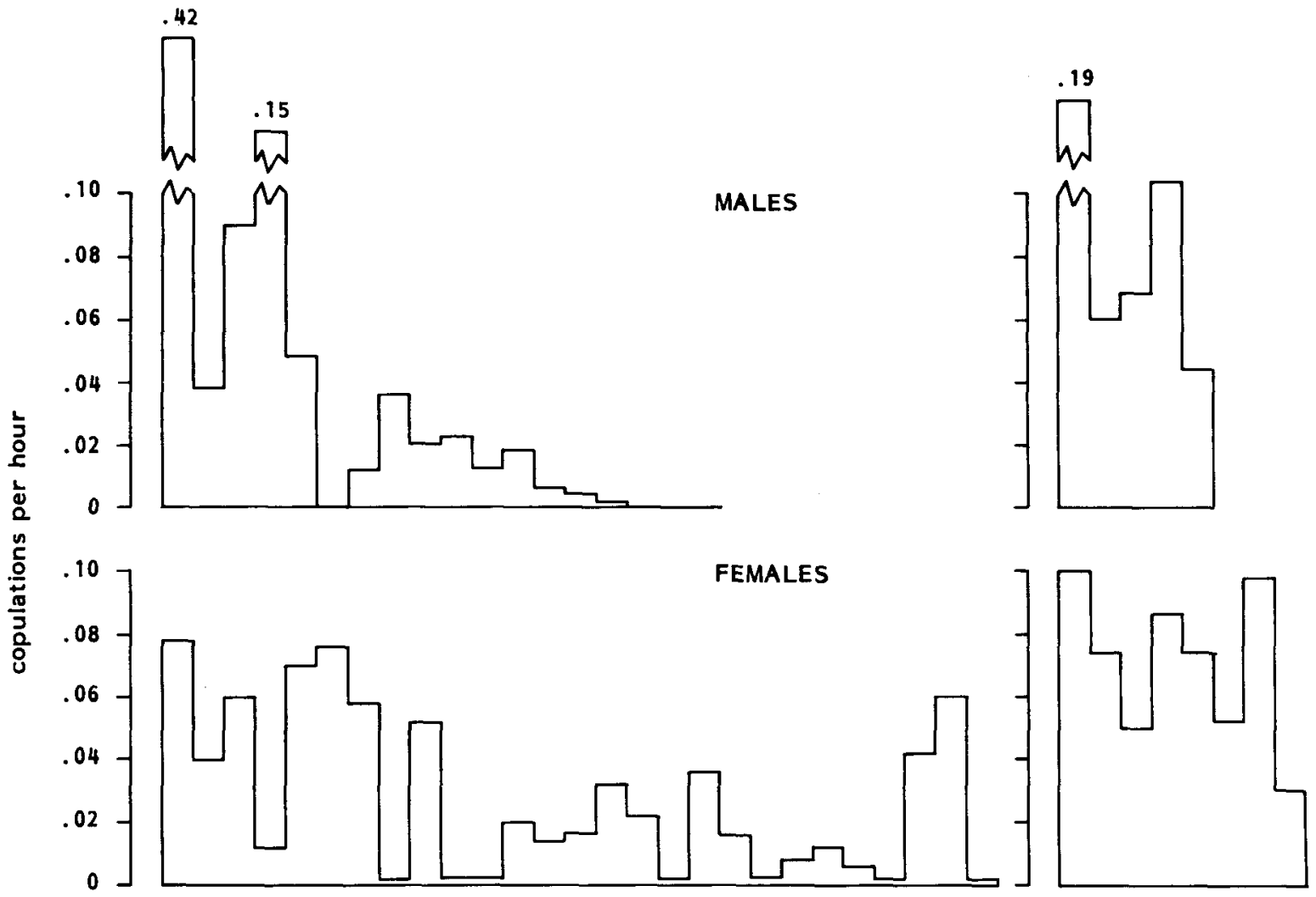

Figure 5. Copulation frequencies (per hour) for males (top) and females (bottom). Each bar represents one individual. Copulations with and without ejaculation are included. Left panels: animals at least 4 years old at the start of the study. Right panels: animals 1.5-3.5 years old at the start of the study. Within each panel, individuals are ordered according to dominance rank (left to right $=$ high to low).

alpha male copulated almost as often as all other adult males combined, whereas the lowest ranking males were never seen to copulate at all.

On several occasions, the highest ranking male or males were temporarily removed from the group. This was done to study the possible changes in the behavior of the remaining animals. The removal of the top male(s) invariably resulted in high sexual activity among the highest ranking remaining males (Estep et al., 1988).

It was during one of these experimental sessions that the maximum number of ejaculations was recorded. In the absence of James and Herman, the third-ranking male (Sam) ejaculated 59 times within $6 \mathrm{~h}$. His partners were a middle-ranking female (Carla) (for the first 7 ejaculations) and the top female (Els). Under normal conditions, with the whole group present in the outdoor cage, the maximum of ejaculations by 1 male on 1 day was "only" 14 . The overall copulation frequency, for all adult males combined, was 0.9 per hour or, if only ejaculations were counted, 0.6 per hour.

Females did not interrupt each other's copulations. High-ranking females appeared to be the favorite partners of top-ranking males (which were the males that copulated most frequently), and therefore copulated more often than middle- and low-ranking females.
A factor much more important than dominance rank in determining female copulatory activity was reproductive state. Females that were either more than 2 months pregnant or lactating did not copulate at all, regardless of rank. Copulations were seen only during periods of ovarian cyclicity and the weeks that immediately preceded or followed such periods (late lactation and early pregnancy). Within ovarian cycles, the fluctuations in copulatory activity in stumptail macaques were not as strong as in other primate species (Nieuwenhuijsen et al., 1986; Slob, Baum, \& Schenck, 1978; Slob, Wiegand, Goy, \& Robinson, 1978).

Copulations by young animals. Before the first birthday, males mounted and females were mounted, but no intromissions were achieved. Mounts with intromission were first seen in males between 1.0 and 2.4 years $(M=1.65)$ and in females between 1.0 and 3.1 years $(M=2.18)$. The tendency for males to start copulating at an earlier age than females was not statistically significant.

Soon after the first intromission, young males began to display the full adult behavioral repertoire, including the frowning round-mouthed look. However, actual ejaculation did not occur until around the 4th birthday.

Copulation frequencies of young males increased more rapidly than those of young females. Before the 2 nd birth- 
day, frequencies were very low in both sexes $(M=0.01$ per hour). During the 3 rd year of life, males copulated much more (between 0.05 and 0.20 times per hour). Their scores were comparable with those of high-ranking adult males (see Figure 5). During puberty and thereafter, no systematic rise or fall in male copulation frequencies occurred.

Female copulation frequencies remained very low until around the 3 rd birthday. About half a year before first ovulation, copulatory activity increased rather suddenly to adult levels. Thereafter, copulation frequencies depended on reproductive state (cyclic, pregnant, or lactating).

Figure 5 shows that young females had rather high copulation frequencies compared with adult females. This was due to two factors. First, most young females studied were daughters of relatively high-ranking mothers. Second, young females had longer periods of sexual activity than adult females. In adult life, periods of sexual activity (during ovarian cycles and early pregnancy) alternated with periods in which no copulations occurred (later pregnancy and lactation). Each active period lasted about 6 months, and inactive periods averaged 15 months. The first sexually active period in a female's life lasted relatively long, since it included not only a period of ovarian cyclicity and early pregnancy, but also the half year preceding first ovulation. Therefore, the total number of sexually active months in young females was relatively high.
In contrast to adult males, prepubertal males could copulate in full view of any high-ranking adult males without being interrupted. Only a small portion of their copulations occurred surreptitiously. This changed around the time of puberty: copulations of pubertal males were increasingly interrupted by higher ranking adults, and the percentage of surreptitious copulations rose steeply to about $90 \%$ at the age of 4 (Figure 6).

Distribution of copulation partners. For males, the distribution of copulation partners depended on dominance rank, and not on age. For females, both dominance rank and age played a role.

From the data above, it can be concluded that prepubertal males copulated mainly with females that were older than themselves, since same-aged females rarely copuated. Like pubertal and adult males, prepubertal males copulated mainly with pubertal and adult females. Topranking males copulated mainly with high-ranking, fully adult partners. Middle and low-ranking males (of any age class) copulated with pubertal and (low-ranking) young adult females. In the absence of top-ranking males, the lower ranking ones also copulated mainly with highranking, fully adult partners.

Females, as they grew older, copulated proportionally more often with high-ranking partners. Before puberty, females copulated at very low frequencies, exclusively with (pre-) pubertal males. Around the 3rd birthday, they

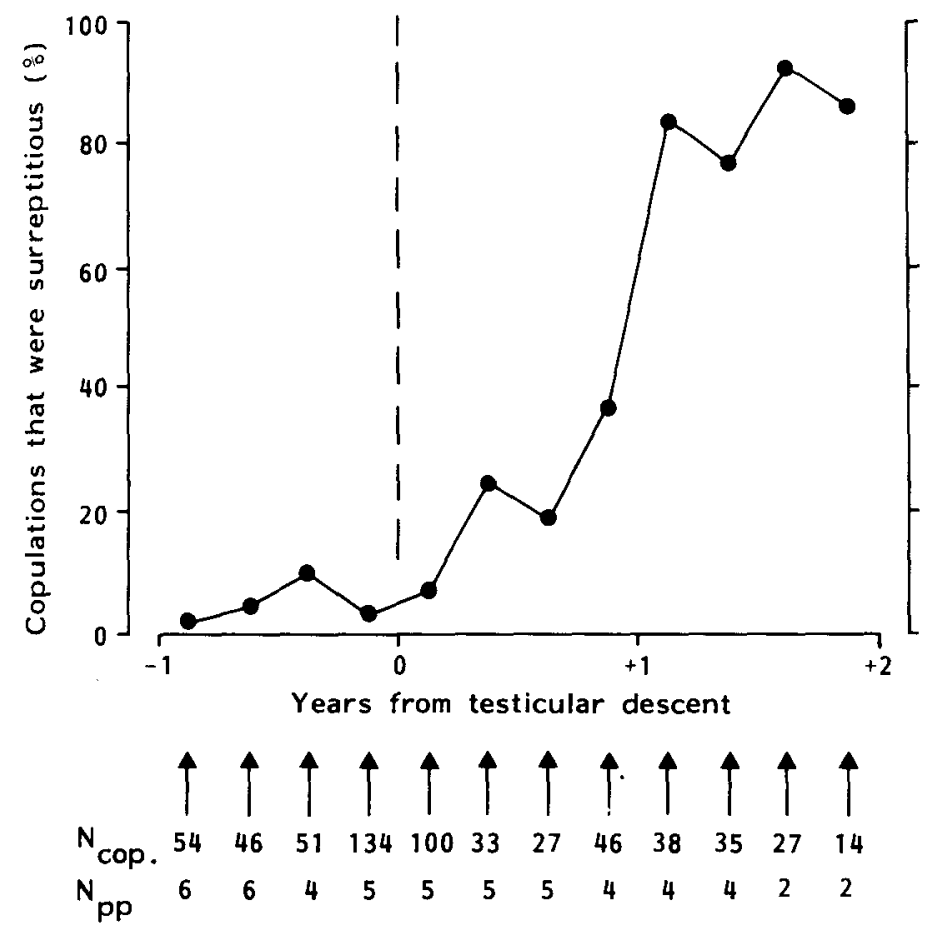

Figure 6. Percentage of copulations that were surreptitious (out of view of any higher ranking adult male), relative to the time of testicular descent. From "Behavioral Aspects of Puberty in Group-Living Stumptail Monkeys (Macaca arctoides)" by K. Nieuwenhuijsen, M. Bonke-Jansen, E. Broekhuijzen, et al., 1988, Physiology \& Behavior, 42, p. 261. Copyright 1988 by Pergamon Press. Reprinted with permission. 
first copulated with adult males, and then first received "real" ejaculations. High-ranking females had more highranking partners than did same-aged low-ranking females.

In a review, Anderson (1986) showed that, throughout the primate world, adult males show a preference for relatively old, multiparous females as sexual partners. Anderson asserted that such females are reproductively more successful than younger females.

Gender differences in sexual development. Figure 7 summarizes the ontogeny of reproductive behavior and physiology in stumptail macaques. It can be seen that males matured faster behaviorally than did females. In rhesus monkeys (Rose, Bernstein, Gordon, \& Lindsley, 1978; Wilson, Gordon, Blank, \& Collins, 1984) and Japanese macaques (Hanby \& Brown, 1974; Takahata, 1980 ), an even greater gender difference in behavioral development was found: males started to copulate as early as our stumptails did, but females did not copulate until puberty ( 2.5 or 3.5 years of age). This is surprising, because males do not mature physiologically faster than do females (Hanby, Robertson, \& Phoenix, 1971; Nieuwenhuijsen, Bonke-Jansen, et al., 1987; Rose et al., 1978; Wilson et al., 1984).

Male macaques start to copulate and have adult sexual partners long before their testosterone levels begin to rise. Therefore, the emergence of sexual activity in males seems to be independent of endogenous hormone levels. This is in line with our findings on the adult male members of the colony, where inter- and intraindividual variations in androgen level did not correlate with differences in behavioral frequencies (Nieuwenhuijsen, de Neef, et al., 1987).

In female macaques, on the other hand, gonadal hormones do seem to play a role in the development of sexual behavior: copulatory activity greatly increased, and females first had adult sexual partners, around the 3rd birthday. Probably around the same age, estrogen levels rose and the first, as yet anovulatory, ovarian cycles occurred. Among the adult females in our group, gonadal hormones were also found to influence copulation frequencies, although this influence was not as strong as in other primate species (Nieuwenhuijsen et al., 1986).

Interference with copulations. When 2 animals were copulating, other animals often approached to interfere with them. Two types of interference were distinguished. Earlier on, it was mentioned that top-ranking males approached and sometimes attacked lower ranking males during copulation. Such interference was named interruption, since it invariably resulted in the immediate separation of the couple. It was done only by adult males that were higher in rank than the copulating male.

The other type of interference was named harassment (Bertrand, 1969; Gouzoules, 1974), which consisted of jumping excitedly around a copulating couple. Harassment often included both aggression (sometimes even biting) and submissive gestures directed at the copulating male. Interestingly, harassment was rarely (1\%) aimed at the copulating female.

Harassment was performed by all classes of animals, except by adult males. Females were most active at the age of 3 to 4 years. In males, harassment rose until the age of 3 , and dropped suddenly at the age of 4 years. High-ranking adult males had the highest harassmentreceived ratio.

In contrast to interruptions, harassment rarely caused the immediate termination of a copulation. Another difference between interruption and harassment was the moment at which they occurred. High-ranking adult males hurried toward a copulating couple as soon as they spotted them, and immediately interrupted them, often before ejaculation had taken place. Harassment, on the other hand, usually began at the time of ejaculation: either the

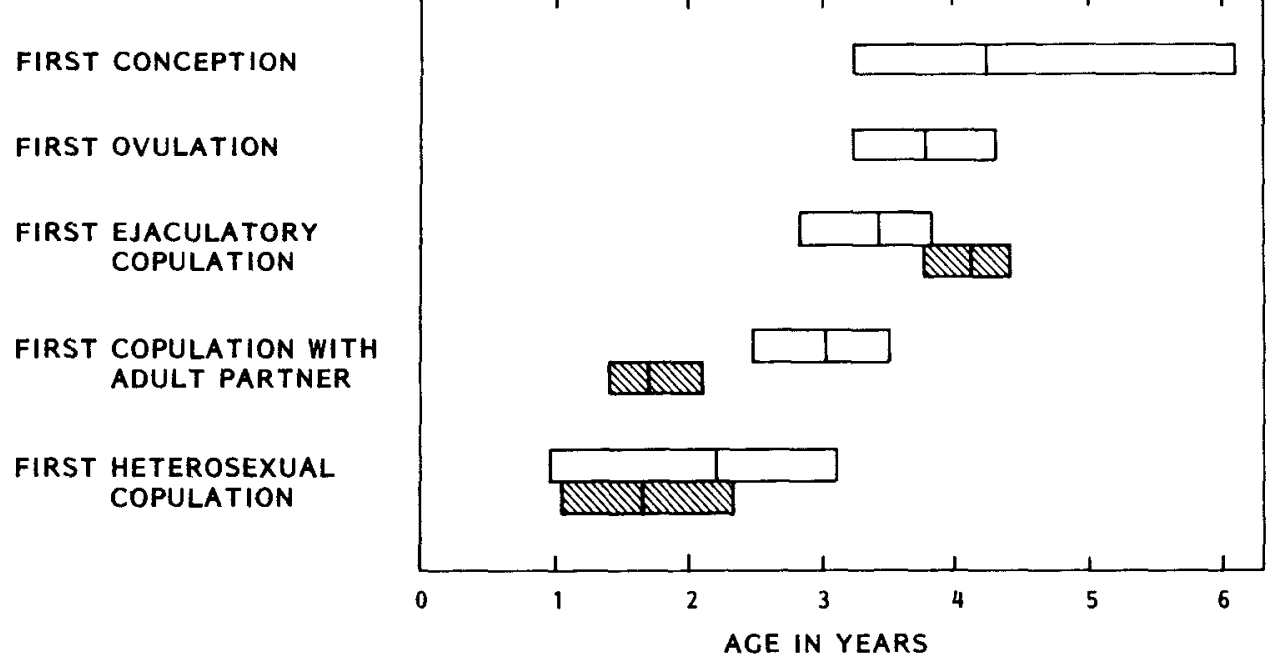

Figure 7. Ontogeny of reproductive capacity; ranges and means for males (hatched bars) and females (open bars). 

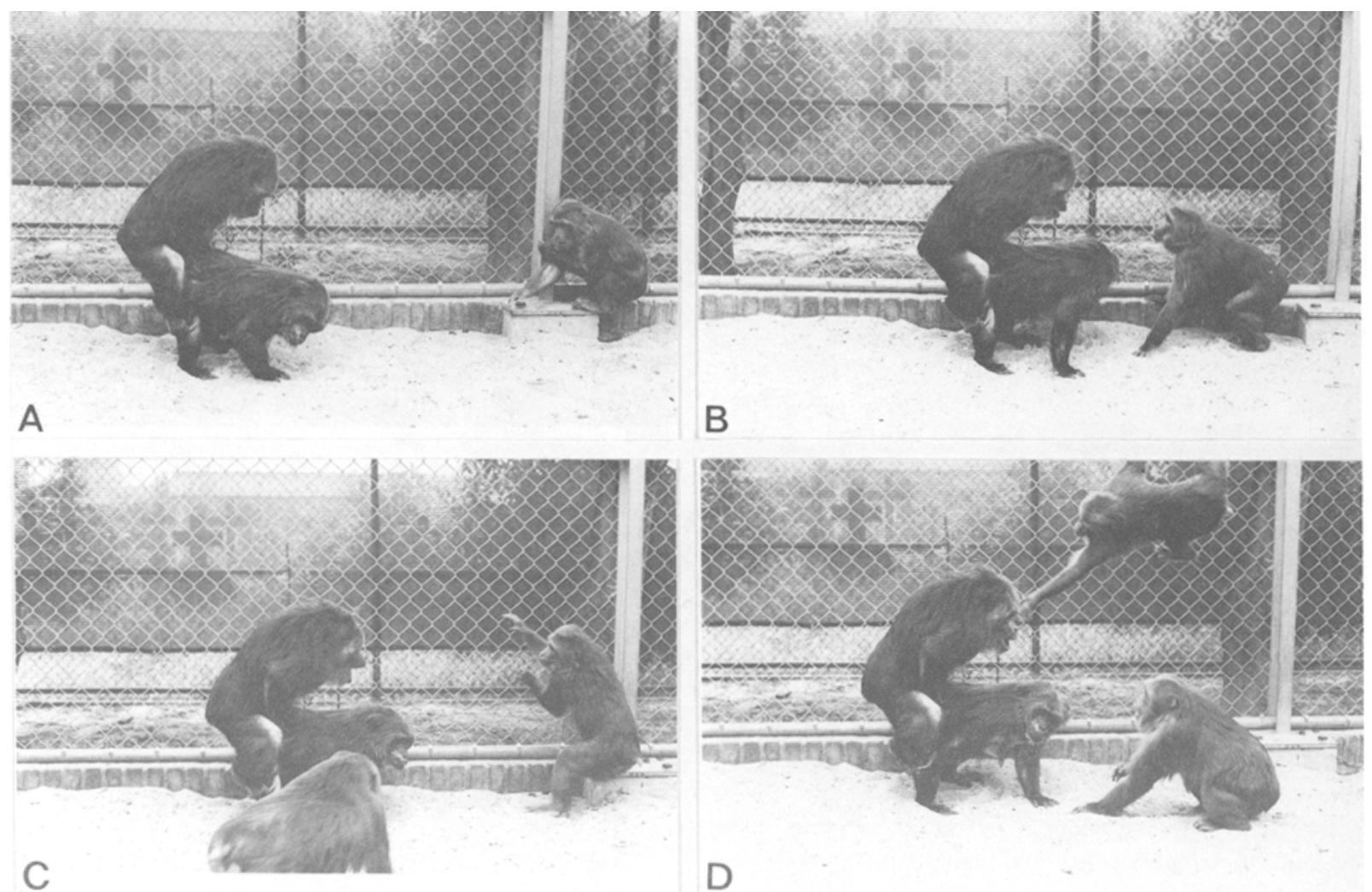

Figure 8. Typical harassment sequence during a copulation of the alpha male (James) with the second-ranking adult female (Sonja). (A) 3-year-old Elvis watches quietly while James makes pelvic thrusts. (B) When the frowning round-mouthed look starts to appear, Elvis jumps toward the couple and gazes at James. (C) Elvis climbs the fence, while 4-year-old Edith approaches. (D) Elvis hits James in the face, while Edith threatens James; the frowning round-mouthed look is clearly visible now.

occurrence of the frowning round-mouthed look or the cessation of pelvic thrusts seemed to trigger the behavior, as is illustrated in Figure 8. In 15\% of the cases observed, the behavior started before ejaculation, and in $14 \%$ sometime thereafter.

A copulating male was usually tolerant toward harassers, even though he was sometimes heavily attacked by them. In about $10 \%$ of the copulations, the male attacked a harasser afterward. Four-year-old males received such "punishments" more often than other harassing animals, which may explain why they ceased to perform harassment.

Copulation interruptions by high-ranking adult males are a common phenomenon among most primate species studied. Harassment by females and youngsters has also been observed among various species, but seems to be most frequent and most intense in stumptail macaques (Niemeyer \& Anderson, 1983). In our colony, harassment occurred in $72 \%$ of the copulations observed.

The reproductive advantages of performing copulation interruptions are obvious, and it is not surprising that this type of interference occurs throughout the primate world. Harassment, on the other hand, is less easy to explain. We have postulated two types of mechanisms: proximate factors, which form the direct cause for the behavior to be performed, and ultimate factors, which imply the reproductive advantages, and thereby explain how the behavior could have evolved and persisted in the species. The latter assumes a genetic basis for performing harassment. The existence of such a basis is hard to prove, but seems likely, because harassment takes the same form in all groups of stumptail macaques studied.

As was noted above, the direct trigger for the behavior seems to be the behavior of the ejaculating male. During ejaculation, the copulating male is temporarily defenseless. It seemed as if females and young animals take advantage of this situation to attack high-ranking adult males. At other times, they never dare do so. Interestingly, females that were often attacked by James also showed a high harassment performance toward him. Harassment may therefore be motivated by feelings of revenge. Data on other males were too few to allow further testing of this hypothesis.

The ultimate advantages of performing harassment remain unclear. There were some indications that harassment may enhance the reproductive potential of the alpha male and thereby, possibly, the inclusive fitness of the performers, many of whom are assumed to be related 
to the alpha male. A copulating male would sometimes dismount to chase away harassers. The alpha male usually $(73 \%)$ resumed his copulations and ejaculated after such an intermission, but other males rarely $(18 \%)$ did so. Furthermore, harassment during copulations of nonalpha males would sometimes attract the attention of a higher ranking male, which would then interrupt the copulation. The chances of being interrupted were $10 \%$ for copulations without harassment and $20 \%$ for copulations with harassment (not counting the alpha male's copulations). However, since harassment usually started at the time of ejaculation, in only a small fraction of the copulations with harassment did ejaculation fail to occur (James, 3\%; other males, $12 \%$ ).

Masturbation. Masturbation in our colony was a highly sex-dimorphic behavior. Females were rarely observed to masturbate. Only four times throughout the entire study period was a female noted to rub her fingers, for a minute or more, over her clitoris and perineal area. In one instance, this coincided with the display of the frowning round-mouthed look.

Masturbation by males, on the other hand, occurred very frequently. For most adult males ( 15 out of 18 ), the major ejaculatory outlet was masturbation rather than copulation. The three exceptions ranked 1, 3, and 4 in the dominance hierarchy. Male masturbation occurred at a total rate of 1.7 times per hour (individual means ranged from 0.01 to 0.54 times per hour; only masturbations resulting in ejaculation were counted). Masturbation frequency of adult males was not correlated with dominance rank or with copulatory activity.

A special type of masturbation is directed masturbation: a male masturbates while looking at or holding the fur of a particular female, or while looking at a copulating couple (see Figure 9). These masturbations, usually directed at females that were high-ranking and relatively old, were performed by all elderly males (10 years or more), with the exception of the alpha male, James. Only

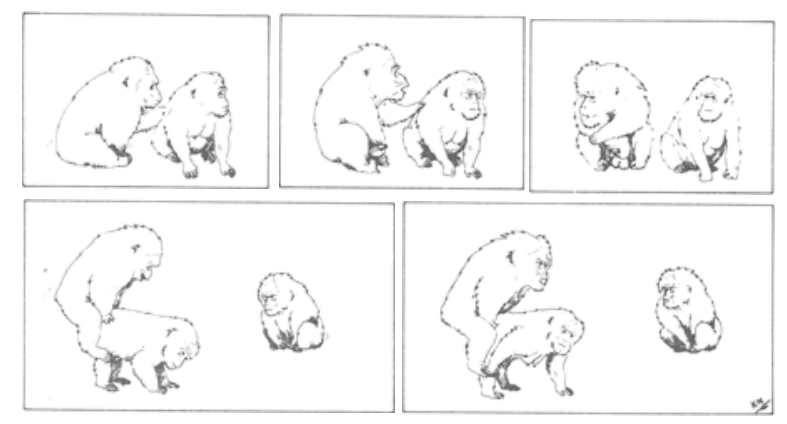

Figure 9. Top, left to right: masturbation directed at a single female; frowning round-mouthed look occurs; semen visible. Bottom, left to right: masturbation directed at a copulating couple; the masturbating and the copulating male ejaculate simultaneously. From "Sexual Behavior During Ovarian Cycles, Pregnancy and Lactation in Group-Living Stumptail Macaques (Macaca arctoides)" by K. Nieuwenhuijsen, K. J. de Neef, and A. K. Slob, 1986, Human Reproduction, 1, p. 160. Copyright 1986 by I.R.L. Press. Reprinted with permission. twice was a younger male seen to masturbate directedly. The frowning round-mouthed look was always shown during directed masturbation, but only rarely during solistic masturbation (in which the male did not look at anybody in particular).

Masturbation (both solistic and directed) could be displayed in full view of higher ranking males, without being interrupted.

\section{SUMMARY}

In this article, gender-related behaviors that were observed during a 3-year study of a large colony of stumptail macaques are reviewed.

The adult members of the group could be ordered in a dominance hierarchy, in which a few males held the top positions, females formed the middle, and both males and females formed the bottom. Pubertal males rose in the hierarchy to subtop positions, whereas pubertal females reached a rank just under their mothers'. Proximity preferences showed a pattern comparable to the central-peripheral structure found in feral macaques. Some young males, but no females, moved from the central to the peripheral part of the group.

Gender differences were found in display behavior and masturbation (almost uniquely masculine behaviors), aggression and social play (males scoring higher than females), and solitary play and social grooming (females scoring higher than males).

Males showed complete copulations (with ejaculation behavior) at the age of 1 , and at the age of 2 or 3 they copulated as frequently as adults. After puberty, their copulations became subject to social control. Females also started to copulate at an early age, but high frequencies and copulations with adult partners did not occur until the age of 3 . Gonadal hormones seemed to influence behavioral development in females, but to a much lesser degree in males.

\section{REFERENCES}

AleXANDER, B. K., \& Bowers, J. M. (1969). Social organization of a troop of Japanese monkeys in a two-acre enclosure. Folia Primatologica, 10, 230-242.

AltmanN, J. (1974). Observational study of behavior: Sampling methods. Behaviour, 49, 227-267.

ANDERSon, C. M. (1986). Female age: Male preference and reproductive success in primates. International Journal of Primatology, 7, 305-326.

ANGST, W. (1975). Basic data concepts on the social organization of Macaca fascicularis. In L. A. Rosenblum (Ed.), Primate behavior: Developments in field and laboratory research (Vol. 4, pp. 325-388). New York: Academic Press.

BernsteIn, I. S. (1969). Stability of the status hierarchy in a pigtail monkey group (Macaca nemestrina). Animal Behaviour, 17, 452-458.

Bernstein, I. S. (1970). Primate status hierarchies. In L.A. Rosenblum (Ed.), Primate behavior: Developments in field and laboratory research (Vol. 4, pp. 71-109). New York: Academic Press.

BERTRAND, M. (1969). The behavioral repertoire of the stumptail macaque: Bibliotheca primatologica (No. 11). Basel/New York: Karger.

BIELERT, C. F., \& GoY, R. W. (1973). Sexual behavior of male rhesus: Effects of repeated ejaculation and partner's cycle stage. Hormones \& Behavior, 4, 109-122. 
Chevalier-Skolnikoff, S. (1974). Male-female, female-male, and male-male sexual behavior in the stumptail monkey, with special attention to the female orgasm. Archives of Sexual Behavior, 3, 95-116.

DEAG, J. M. (1977). Aggression and submission in monkey societies. Animal Behaviour, 25, 465-474.

DE WAAL. F. B. M. (1977). The organization of agonistic relations within two captive groups of Java-monkeys (Macaca fascicularis). Zeitschrift für Tierpsychologie, 44, 225-282.

DE WAAL, F. B. M. (1982). Chimpanzee politics. London: Jonathan Cape.

DE WAal, F. B. M., \& LutTrell. L. M. (1986). The similarity principle underlying social bonding among female rhesus monkeys. Folia Primatologica, 46, 215-234.

Ea ton, G. G., \& Resko, J. A. (1974). Plasma testosterone and male dominance in a Japanese macaque (Macaca fuscata) troop compared with repeated measures of testosterone in laboratory males. Hormones \& Behavior, 5, 251-259.

Enomoto. T., Seikı, K., Haruki, Y. (1979). On the correlation between sexual behavior and ovarian hormone level during the menstrual cycle in captive Japanese monkeys. Primates, 20, 563570 .

Estep, D. Q., Nieuwenhuijsen, K., Bruce, E. M., de Neef, K. J., Walters, P. A., Baker, S. C., \& Slob, A. K. (1988). Inhibition of sexual behaviour among subordinate stumptail macaques (Macaca arctoides). Animal Behaviour, 36, 854-864.

Fedigan, L. M. (1982). Primate paradigms: Sex roles and social bonds. Montreal: Eden Press.

Fooden, J., Guoqiang, Q., Zongren, W., \& Yingxiang, W. (1985). The stumptail macaques of China. American Joumal of Primatology, 8, 11-30.

Goldfoot, D. A., Westerborg-Van Loon, H., Groeneveld, W., \& SloB, A. K. (1980). Behavioral and physiological evidence of sexual climax in the female stump-tailed macaque (Macaca arctoides). Science, 208, 1477-1479.

Gorbon, T. P. (1981). Reproductive behavior in the rhesus monkey: Social and endocrine variables. American Journal of Zoology, 21, 185-195.

Gordon, T. P., Rose, R. M., \& Bernstein, I. S. (1976). Seasonal rhythm in plasma testosterone levels in the rhesus monkey (Macaca mulatta): A three year study. Hormones \& Behavior, 7, 229-243.

Gouzoules, H. (1974). Harassment of sexual behavior in the stumptail macaque, Macaca arctoides. Folia Primatologica, 22, 208-217.

GoY, R. A., \& GoldFoOt, D. A. (1973). Hormonal influences on sexually dimorphic behavior. In R. O. Greep \& E. B. Astwood (Eds.), Handbook of physiology (Section 7, Endocrinology, Vol. II, Part I, pp. 169-186). Washington: American Physiological Society.

Hanby, J. P., \& Brown, C. E. (1974). The development of socio-sexual behaviours in Japanese macaques Macaca fuscata. Behaviour, 49, 152-196.

Hanby, J. P., Robertson, L. T., \& Phoenix, C. H. (1971). The sexual behavior of a confined troop of Japanese macaques. Folia Primatologica, 16, 123-143.

Johnson, D. F., Modahl, K. B., \& Eaton, G. G. (1982). Dominance status of adult male Japanese macaques: Relationship to female dominance status, male mating behaviour, seasonal changes, and developmental changes. Animal Behaviour, 30, 383-392.

KaufmanN, J. H. (1967). Social relations of adult males in a free-ranging band of rhesus monkeys. In S. A. Altmann (Ed.), Social communication among primates (pp. 73-98). Chicago: Chicago University Press.

KoFoRD, C. B. (1963). Rank of mothers and sons in bands of rhesus monkeys. Science, 141, 356-357.

LINDBURG, D. G. (1987). Seasonality of reproduction in primates. Comparative Primate Biology, 2B, 167-218.

Masters, W. H., \& Johnson, V. E. (1966). Human sexual response. Boston: Little Brown.

Modahl, K. B., \& Eaton, G. G. (1977). Display behaviour in a con- fined troop of Japanese macaques (Macaca fuscata). Animal Behaviour, 25, 525-535

NAdLeR, R. D., \& Rosenblum, L. A. (1973). Sexual behavior during successive ejaculations in bonnet and pigtail macaques. American Journal of Physical Anthropology, 38, 217-220.

Niemeyer, C. L., \& Anderson, J. R. (1983). Primate harassment of matings. Ethology \& Sociobiology, 4, 205-220.

Nieumenhuijsen, K., Bonke-Jansen, M., Broekhuijzen, E., dE NeEF, K. J., van Hooff, J. A. R. A. M., VAN deR WerfF ten BoSCH, J. J., \& SLOB, A. K. (1988). Behavioral aspects of puberty in group-living stumptail monkeys (Macaca arctoides). Physiology \& Behavior, 42, 255-264.

Nieuwenhuiusen, K., Bonke-Jansen, M., De NeEF, K. J., VAN der Werff ten Bosch, J. J., \& SLob, A. K. (1987). Physiological aspects of puberty in group-living stumptail monkeys (Macaca arctoides). Physiology \& Behavior, 41, 37-46.

Nieuwenhulusen, K., De Neef, K. J., \& Slob, A. K. (1986). Sexual behaviour during ovarian cycles, pregnancy and lactation in groupliving stumptail macaques (Macaca arctoides). Human Reproduction, 1, $159-169$.

Nieuwenhulusen, K., de Neef, K. J., Van der Werff ten Bosch, J. J., \& SLOB, A. K. (1987). Testosterone, testis size, seasonality, and behavior in group-living stumptail macaques (Macaca arctoides). Hormones \& Behavior, 21, 153-169.

Nieuwenhuijsen, K. Lammers, A. J. J. C., de Neef. K. J., \& Slob, A. K. (1985). Reproduction and social rank in female stumptail macaques (Macaca arctoides). International Journal of Primatology, 6 , 77-99.

Nieuwenhuijsen, K., Slob, A. K., \& DE NeEF, K. J. (1988). Fetal gender and aggression in pregnant stumptail monkeys (Macaca arctoides). Developmental Psychobiology, 20, 277-282.

Nigi, H., Tiba, T., Yamamoto, S., Floescheim, Y., \& Ohsawa, N. (1980). Sexual maturation and seasonal changes in reproductive phenomena of male Japanese monkeys (Macaca fuscata) at Takasakiyama. Primates, 21, 230-240.

PACKER, C. (1979). Inter-troop transfer and inbreeding avoidance in Papio anubis. Animal Behaviour, 27, 1-36.

Rose, R. M., Bernstein, I. S., Gordon, T. P., \& Lindsley, J. G. (1978). Changes in testosterone and behavior during adolescence in the male thesus monkey. Psychosomatic Medicine, 40, 60-70.

Simonds, P. E. (1965). The bonnet macaque in South India. In I. DeVore (Ed.), Primate behavior: Field studies on monkeys and apes (pp. 175-196). New York: Holt, Rinehart \& Winston.

Slob, A. K., BaUm, M. J., \& SChENCK, P. E. (1978). Effects of the menstrual cycle, social grouping, and exogenous progesterone on het erosexual interaction in laboratory-housed stumptail macaques ( $M$. arctoides). Physiology \& Behavior, 21, 915-921.

Slob, A. K., Groeneveld, W. H., \& van der WerfF ten Bosch, J. J. (1986). Physiological changes during copulation in male and fe male stumptail macaques (Macaca arctoides). Physiology \& Behavior, 38, 891-895.

Slob, A. K., \& NieuWenhuiJsen, K. (1980). Heterosexual interactions of pairs of laboratory-housed stumptail macaques (Macaca arc toides) under continuous observation with closed-circuit video recording. International Joumal of Primatology, 1, 63-80.

Slob, A. K., Wiegand, S. J., Goy, R. W., \& Robinson, J. A. (1978). Heterosexual interactions in laboratory-housed stumptail macaques (Macaca arctoides): Observations during the menstrual cycle and af ter ovariectomy. Hormones \& Behavior, 10, 193-211.

Southwick, C. H., BEG, M. A., \& SidDIQI, M. R. (1965). Rhesus monkeys in North India. In I. DeVore (Ed.), Primate behavior (pp. 111159). New York: Holt, Rinehart \& Winston.

SugrYama, Y. (1960). On the division of a natural troop of Japanese monkeys at Takasakiyama. Primates, 2, 109-149.

TAKAHATA, Y. (1980). The reproductive biology of a free-ranging troop of Japanese monkeys. Primates, 21, 303-329.

TAUB, D. M. (1980). Female choice and mating strategies among wild 
barbary macaques (Macaca sylvanus L.). In D. G. Lindburg (Ed.), The macaques: Studies in ecology, behavior and evolution (pp. 287344). New York: Van Nostrand Reinhold.

WiLson, A. P., \& VesSEY, S. H. (1968). Behavior of free-ranging castrated rhesus monkeys. Folia Primatologica, 9, 1-14.

Wilson, A. P., Gordon, T. P., Blank, M. S., \& Collins, D. C. (1984). Timing of sexual maturity in female rhesus monkeys (Macaca mulatta) housed outdoors. Journal of Reproduction \& Fertility, 70, 625-633.
WoLFE, L. D. (1981). Display behavior of three troops of Japanese macaques (Macaca fuscata). Primates, 22, 24-32

ZUMPE, D., \& Michael, R. P. (1968). The clutching reaction and orgasm in the female rhesus monkey (Macaca mulatta). Journal of Endocrinology, 40, 117-123.

(Manuscript received March 22, 1988.) 